\title{
URBAN STREET CANYONS - IMPACT OF DIFFERENT MATERIALS AND COLOURS OF FACADES AND GROUND AND DIFFERENT POSITIONS OF PERSONS ON OUTDOOR THERMAL COMFORT
}

\author{
UDO DIETRICH \\ REAP research group (resource efficiency in architecture and planning), \\ HafenCity University Hamburg, Germany.
}

\begin{abstract}
Outdoor thermal comfort in urban street canyons has become, in times of adaptation to climate change, an important field of research also for cities in moderate climates. Many investigations can be found dealing with measurements of façade and ground temperatures, solar radiation, wind, etc. The impact of different materials, colors, low emissivity paints, green facades, etc. is widely discussed. To have the possibility to compare and assess these different measures a simple but holistic model based on standard VDI 3787 ('Klima-Michel model') was developed. It is extended by a model for the dynamic behavior of materials using only known physical parameters of the materials. This model shows good accordance with measurements but can be used independently of measurements and for all materials and locations. The assessment is done with the Universal Thermal Comfort Index (UTCI). The whole model is described in this paper. In the second part of the paper a street canyon with height to width ratio 1:1 was investigated for a moderate / Mediterranean climate (Bern). Different measures for the reduction of heat stress are investigated, compared and could be finally classified in a list of priorities regarding their impact. Shading has highest impact, less of the persons (sun umbrellas, awnings, trees) but more of the whole canyon (fabric, big trees). Green facades and low emissivity paints reduce heat stress remarkably. Very bright materials increase heat stress because of their high reflection of solar radiation from facades and ground to the persons in the canyon (this effect was found as dominating the corresponding reduction of IR radiation from the absorbing material to the persons). The influence of massive versus light materials is quite low.

Keywords: comfort in hot periods, impact of different materials and colors, outdoor thermal comfort, Universal Thermal Comfort Index UTCI, Urban street canyon.
\end{abstract}

\section{INTRUDUCTION}

The reaction to climate change requires also adaptation of our cities. The topic of this paper is thermal outdoor comfort in urban street canyons under summer conditions (hot periods). Most efficient measures to hold temperatures in acceptable ranges are ventilation channels through the cities and the reduction of sealed surfaces and thus of urban scale. But especially in street canyons also local measures like material and color of façades and ground, green facades and shading have a remarkable influence.

Different models exist to describe outdoor thermal comfort. Best validated is the Universal Thermal Comfort Index UTCI [1].

There is a lot of literature regarding different measures to influence thermal comfort, measurements as well as simulations [2-8]. But the different papers deal often with only one or a few of these measures; it is very difficult to assess the impact of all measures together and in comparison.

For that reason a model was developed that can simulate all measures at the same time allowing comparisons and a development of a list of priorities of the most effective measures. Especially for the dynamic behavior of materials in air temperature and under solar radiation a physical model is described and found in good accordance with measurements. That model 
describes the thermal outdoor comfort only by known physical quantities of materials, orientation and the geometry of the street canyon. The results are derived for a hot summer day with high solar radiation in moderate to Mediterranean climate (Bern) and a typical (infinite) street canyon in east-west orientation. That means that one façade is south oriented and receives direct solar radiation from sun while the opposite north façade is most of the time in shadow. The model allows consideration of different positions of a person in the canyon. That allows to compare and to assess the influence of both facades on comfort.

\section{BASIC MODEL FOR INVESTIGATION}

\subsection{The UTCI assessment scale}

The final calculation of UTCI can be done by software from UTCI website [2], the formula can be downloaded too. UTCI is directly connected with a scale of perceived thermal comfort [9]:

\subsection{The 'Klima-Michel' model}

Outdoor thermal comfort is determined by air temperature, humidity, wind velocity, clothing, activity and widely by mean radiant temperature. For the determination of the mean radiant temperature Tmrt the 'Klima-Michel' model is widely used and described in the German standard VDI 3787 part 2 [10]. Tmrt is determined by:

- Direct as well as diffuse solar radiation from sun direct to person

- Direct as well as diffuse solar radiation from sun reflected from walls and ground to person

- Infrared radiation from walls, ground and sky to person

For the purposes of this paper the model was rewritten in an excel sheet. Geometrical input parameters are:

- Width and height (both side identical) of street canyon

- Position of the person in the canyon (left / right on a sidewalk or in the middle simulating a pedestrian zone or a place situation)

\begin{tabular}{|c|c|c|}
\hline UTCI $\left({ }^{\circ} \mathrm{C}\right)$ range & Stress Category \\
\hline above +46 & extreme heat stress & \\
\hline+38 to +46 & very strong heat stress & \\
\hline+32 to +38 & strong heat stress & \\
\hline+26 to +32 & moderate heat stress & \\
\hline+9 to +26 & no thermal stress & \\
\hline+9 to 0 & slight cold stress & \\
\hline 0 to -13 & moderate cold stress & \\
\hline-13 to -27 & strong cold stress & \\
\hline-27 to -40 & very strong cold stress & \\
\hline below -40 & extreme cold stress & \\
\hline
\end{tabular}

Figure 1: UTCI assessment scale of perceived thermal comfort in degrees Celsius, verbal description and color. 
For the distribution of radiation in the canyon and to the person different view factors are necessary. They are described in a lot of literature and also in the web [11]. Because of the fixed geometry of street canyon and person only a small number of view factor formulas is necessary. Material characteristics for facades (left and right different) and ground are:

- Heavy or light (concrete, brick, plaster on thermal insulation or cladding)

- Color (corresponding to Albedo and thus absorption and reflection of received solar radiation)

- Emissivity for infrared radiation

\section{CHOSEN LOCATION BERN, WEATHER DATA FOR HOT SUMMER DAY AND BASIC ASSESSMENT WITH UTCI SCALE}

As location for the investigation the city of Bern was chosen. It is a good representative for a moderate to Mediterranean climate. The data were generated from Meteonorm [12]. The hottest day with highest solar radiation was found in the beginning of July (see Fig. 2).

The concentration on a period of only $24 \mathrm{~h}$ includes implicates that all materials (walls / ground) that heat up during the day will completely cool down in the following night so that the next $24 \mathrm{~h}$ period starts with the same conditions. Literature and own measurements confirm this assumption as realistic (see Chapter 4).

For the assessment with UTCI wind velocity and humidity are taken as constant values (average over the 24 hours of chosen day). This was done to avoid that effects in focus in this investigation (impact of different materials) are influenced by changing wind and humidity. The average values are $0.9 \mathrm{~m} / \mathrm{s}$ for wind and $15.9 \mathrm{hPa}$ for water vapor pressure.

The basic assessment with UTCI assumes that there is no influence by Tmrt, thus setting Tmrt =Tair. The resulting UTCI holds for the absolute optimal summer comfort conditions without any hot wall / ground (see Fig. 3). The corresponding line will be included for comparison in all other graphs with the results. In the afternoon we have an unavoidable slight heat stress already because of air temperature. A further increase because of warm surfaces could reach higher values on the UTCI scale - the impact of different influences and measures should be visible clearly!

\section{ASSUMPTIONS FOR DYNAMIC BEHAVIOR OF MATERIALS}

The surface temperature of facades and ground is determined by the outdoor air temperature, infrared radiation exchange with cold and clear sky and absorbed direct or diffuse solar

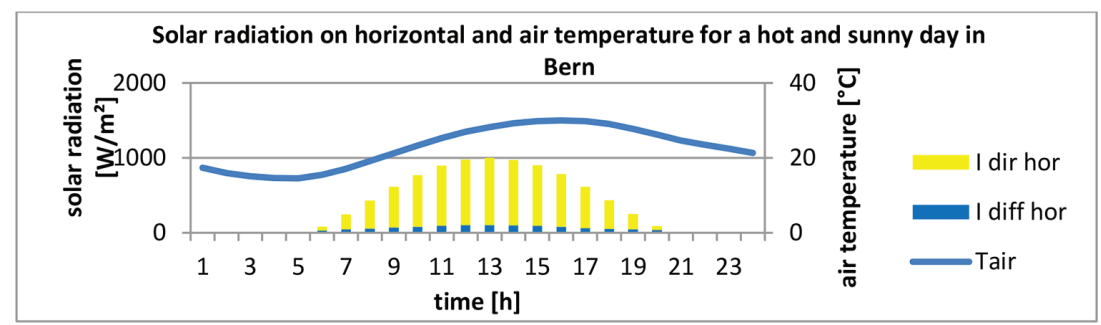

Figure 2: Solar radiation (separated in direct and diffuse I dir hor and I dif hor resp.) on a horizontal surface and temperature for the chosen hot and sunny day in moderate to Mediterranean climate of Bern 


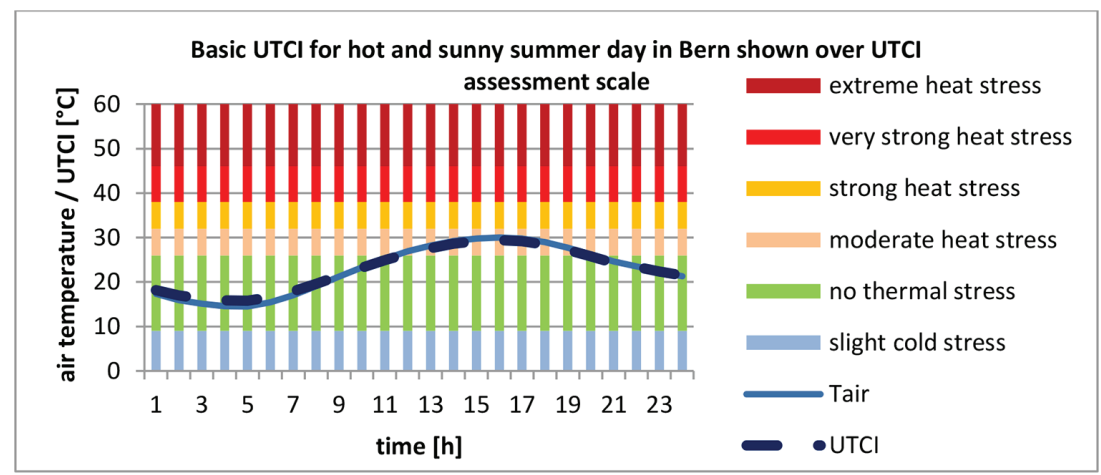

Figure 3: Basic UTCI for the hot and sunny day in Bern as base for the optimal situation. The assumption here is that Tmrt is equal to Tair, that situation can not be reached in reality.

radiation. In chapter 4.2 the behaviour in air temperature and in radiative exchange with sky is regarded, in chapter 4.3 the influence of absorbed solar radiation is added. In 4.1 is investigated which thickness of the last layer of the construction is really active in the exchange of thermal energy and thus determining the surface temperature.

\subsection{The thickness of the active layer of materials in facades and ground}

Materials interact dynamically with outdoor temperature and solar radiation in a $24 \mathrm{~h}$ period. It is known that only the first about 10 to $20 \mathrm{~cm}$ of a material are in active contact with the surroundings. The thickness of the active layer ('penetration depth') can be determined following theory of temperature waves with:

$$
\text { Active layer }=\operatorname{SQRT}(\lambda /(\rho * \mathrm{c} * \mathrm{PI} * \mathrm{f})) \quad[\mathrm{m}]
$$

\section{$\lambda$ thermal conductivity $\quad \mathrm{W} / \mathrm{mK} \quad \rho$ density $\quad\left[\mathrm{kg} / \mathrm{m}^{3}\right]$ \\ c specific heat capacity $\mathrm{Wh} / \mathrm{kgK} \quad \mathrm{f}$ frequency (here $1 / 24 \mathrm{~h}$ )}

Thermal comfort in street canyons depends on the temperature of the material surfaces and not on the temperatures in deeper layers of the material. That's why it can be assumed that for adaption to the real behaviour of surface temperatures the thickness of the active layer should be reduced. This reduction and the corresponding dynamic thermal behaviour of the materials is the parameter to adapt to measurements and other models [3-5]. The best correlation was found for:

$$
\text { Active layer for surface temperature }=0.45 * \text { active layer }
$$

Air and thermal insulation do not transfer heat exchange to deeper layers. Thus for some constructions the active thickness is given by the thickness of the layer itself (plaster on thermal insulation, cladding, wood). Table 1 gives an overview over the used material values.

4.2 The temperature behaviour of material's surfaces in the course of a day caused by air temperature and cloudy and clear sky.

The outdoor air temperature is following a sinus function with a time period of $24 \mathrm{~h}$ and described by a mean value, amplitude and time shift relative to midnight. 
Table 1: Specific physical values of materials and thickness of active layer for surface temperatures.

\begin{tabular}{|c|c|c|c|c|c|c|c|}
\hline & & WS/kgK & $\mathrm{kg} / \mathrm{m}^{3}$ & $\mathrm{~W} / \mathrm{mK}$ & - & - & $\mathrm{m}$ \\
\hline & & $\begin{array}{l}\text { specific } \\
\text { heat } \\
\text { capacity }\end{array}$ & density & $\begin{array}{l}\text { thermal } \\
\text { conduc- } \\
\text { tivity }\end{array}$ & $\begin{array}{l}\text { albedo } \\
\text { short } \\
\text { wave }\end{array}$ & $\begin{array}{l}\text { emissivity } \\
\text { long wave }\end{array}$ & $\begin{array}{l}\text { active layer } \\
\text { for surface } \\
\text { temperature }\end{array}$ \\
\hline \multicolumn{8}{|l|}{ facade materials } \\
\hline \multirow[t]{2}{*}{ brick } & bright & 1000 & 1400 & 0.58 & 0.70 & 0.90 & 0.048 \\
\hline & dark & 1000 & 1400 & 0.58 & 0.30 & 0.90 & 0.048 \\
\hline \multirow[t]{2}{*}{ plaster } & bright & 1000 & 1800 & 1.00 & 0.70 & 0.90 & 0.005 \\
\hline & dark & 1000 & 1800 & 1.00 & 0.30 & 0.90 & 0.005 \\
\hline wood & & 1600 & 700 & 0.18 & 0.50 & 0.90 & 0.020 \\
\hline \multirow[t]{2}{*}{ cladding (mineral) } & bright & 1500 & 1200 & 0.23 & 0.70 & 0.90 & 0.015 \\
\hline & dark & 1500 & 1200 & 0.23 & 0.30 & 0.90 & 0.015 \\
\hline \multirow[t]{2}{*}{ concrete } & grey & 1000 & 2400 & 2.00 & 0.25 & 0.90 & 0.068 \\
\hline & bright & 1000 & 2400 & 2.00 & 0.70 & 0.90 & 0.068 \\
\hline \multirow[t]{2}{*}{ aerated concrete } & bright & 1000 & 600 & 0.19 & 0.70 & 0.90 & 0.042 \\
\hline & dark & 1000 & 600 & 0.19 & 0.30 & 0.90 & 0.042 \\
\hline \multicolumn{8}{|l|}{ ground materials } \\
\hline \multicolumn{2}{|l|}{ tarmac } & 1000 & 2100 & 0.70 & 0.15 & 0.90 & 0.043 \\
\hline \multicolumn{2}{|c|}{ natural stone (pavement) } & 1000 & 2600 & 2.30 & 0.25 & 0.90 & 0.070 \\
\hline \multicolumn{2}{|l|}{ marble } & 1000 & 2800 & 3.50 & 0.60 & 0.90 & 0.083 \\
\hline concrete & grey & 1000 & 2400 & 2.00 & 0.25 & 0.90 & 0.068 \\
\hline
\end{tabular}

For the estimation of the surface temperature of facades and ground in contact with outdoor air the physical model of an infinite extended and thin plate can help. The temperature in the material follows of course also a sinus function but with different amplitude (described by decrement in regard to amplitude of air temperature) and time shift (supplementary to the one of air temperature in regard to midnight). The corresponding solution of the heat transfer equation can also be derived analytically [13]. Central quantity is Stanton's number St, Table 2 shows the resulting quantities of the chosen materials.

$$
\mathrm{St}=\alpha /((\rho * \mathrm{c} * \mathrm{~d} * 2 \mathrm{PI} * \mathrm{f}) \quad[-]
$$

$a$ heat transfer coefficient (convective and radiative) $\quad\left[\mathrm{W} / \mathrm{m}^{2} \mathrm{~K}\right]$

$\mathrm{d}$ thickness of active layer (see eqn. (2)) [m]

$$
\begin{aligned}
& \text { decrement }=\mathrm{St} / \operatorname{SORT}(1+\mathrm{St} * \mathrm{St}) \quad[0, \ldots, 1] \\
& \text { time shift }= \arctan (1 / \mathrm{St}) \quad[0, \ldots, \mathrm{PI} / 2] \\
&(\mathrm{PI} / 2 \text { corresponds with a time shift of } 6 \mathrm{~h})
\end{aligned}
$$

Measurements [3] show that because of the cooling effect of the cold and clear sky surface temperatures fall below air temperature in night. Consequently that results in a mean value 
Table 2: Dynamic thermal properties of chosen materials, decrement and time shift.

\begin{tabular}{lll}
\hline & - & $\mathrm{h}$ \\
\cline { 3 - 3 } & decrement & time shift \\
\hline facade materials & 0.97 & 0.96 \\
Brick, bright and dark & 1.00 & 0.13 \\
Plaster, bright and dark & 1.00 & 0.33 \\
wood & 0.99 & 0.39 \\
cladding (mineral), dark and bright & 0.85 & 2.13 \\
Concrete, grey and bright & 1.00 & 0.37 \\
aerated concrete, dark and bright & & \\
ground materials & 0.95 & 1.27 \\
tarmac & 0.82 & 2.32 \\
natural stone (pavement) & 0.75 & 2.78 \\
marble & 0.85 & 2.13 \\
Concrete, grey & &
\end{tabular}

which is lower than the one of air temperature. The mean value is set in way that the surface temperature during night falls $2 \mathrm{~K}$ below air temperature. Figure 4 shows the behaviour of façade and ground materials in air temperature.

The real temperature (Tair, data) behaviour was approached by a sinus function (Tair, sinus) with very good correlation. The temperatures of the different materials show clearly decrement and time shift in regard to Tair. The lightest materials (plaster, cladding, wood) with the smallest impact, the heaviest (concrete, pavement, marble) with the highest.

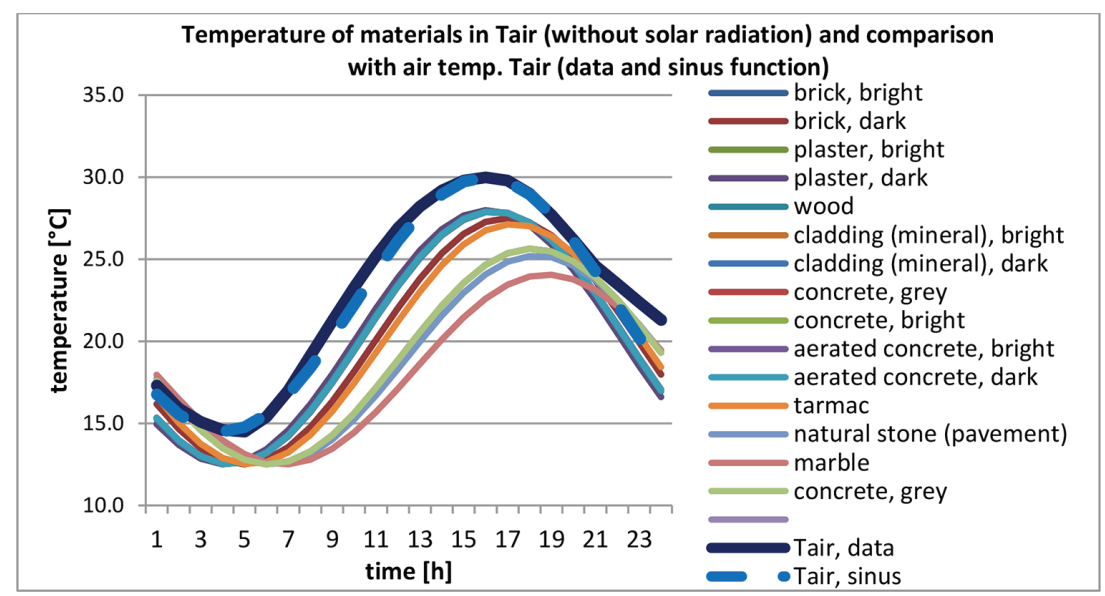

Figure 4: Temperature behaviour of chosen materials in outdoor air and radiation exchange with cold and clear sky. 
4.3 Temperatures of surfaces of façade and ground materials as consequence of absorbed solar radiation.

The increase of temperature of façade and ground materials under the sun is measured and described quite often [3-5]. But also here it is very difficult to develop a general method for the description of material behaviour, the documentation is mostly insufficient (missing information about surrounding temperature, insolation, material quantities etc.).

It is not possible to derive an analytical solution of the heat transfer equation because there is more than one dynamic quantity in (temperature of the material, air temperature and solar radiation!). To solve the problem a simple energy balance model is developed which assumes that all these quantities behave in way that they are constant for one hour and change then for the next hour etc. Indices 0 stand for the present time step, -1 for the one hour before. We regard the development from time $=-1$ to time $=0$.

change in internal energy = energy gains (from insolation)

$$
\text { - energy losses (convective and radiative to Tair) [Wh] }
$$

$$
\mathrm{m} * \mathrm{c} *(\mathrm{~T}(0)-\mathrm{T}(1))=\mathrm{I}_{\text {solar }}(0) * \mathrm{~A} * 1 \mathrm{~h}-a * \mathrm{~A} * 1 \mathrm{~h} *(1 / 2 *(\mathrm{~T}(0)+\mathrm{T}(-1)-\mathrm{Tair}(0))
$$

$\begin{array}{lll}a & \begin{array}{l}\text { heat transfer coefficient (convective and radiative) } \\ \text { absorbed part of solar radiation (direct and diffuse!) }\end{array} & {\left[\mathrm{W} / \mathrm{m}^{2} \mathrm{~K}\right]} \\ \mathrm{I}_{\text {solar }} & \begin{array}{l}\text { striking on surface of material } \\ {\left[\mathrm{W} / \mathrm{m}^{2}\right]}\end{array} \\ \text { Tair } & \text { temperature of air (see chapters 3 and 4.2) } & {\left[{ }^{\circ} \mathrm{C}\right]} \\ \text { c } & \text { specific heat capacity } & {[\mathrm{Wh} / \mathrm{kgK}]} \\ \text { A } & \text { surface area of material, simply set to } 1 \mathrm{~m}^{2} & {\left[\mathrm{~m}^{2}\right]}\end{array}$

The heat loss is related to half of the temperature difference between $\mathrm{T}(0)$ and $\mathrm{T}(1)$. That would be correct if we assume a linear increase in $\mathrm{T}$ for the selected single hour.

The mass of the material can be replaced by $\left(\rho-\right.$ density $\left[\mathrm{kg} / \mathrm{m}^{3}\right], \mathrm{d}-$ thickness of active layer of material [m], see eqn (2)):

$$
\mathrm{m}=\rho * \mathrm{~A} * \mathrm{~d} \quad[\mathrm{~kg}]
$$

Transferring the equation to $\mathrm{T}(0)$ ends with:

$$
\begin{aligned}
\mathrm{T}(0)= & (1 /(1 / 2+(\rho * \mathrm{~d} * \mathrm{c}) /(\alpha * 1 \mathrm{~h})) * \\
& \left.\left(\operatorname{Tair}(0)+\mathrm{I}_{\text {solar }} / \alpha+\mathrm{T}(-1) *((\rho * \mathrm{~d} * \mathrm{c}) /(\alpha * 1 \mathrm{~h})-1 / 2)\right)\right) \quad\left[{ }^{\circ} \mathrm{C}\right]
\end{aligned}
$$

This equation describes already the behaviour of the material under solar radiation. However, in the case that there is no solar radiation (Isolar $=0$ ), the resulting temperature $\mathrm{T}(0)$ must of course be identical to Tair( 0$)$. To balance that, a supplementary correction term must be added (that corresponds to the 'constant' after an integration, which has to be determined by boundary conditions).

The complete equation with this correction term is:

$$
\begin{aligned}
& \mathrm{T}(0)=\left(1 /(1 / 2+(\rho * \mathrm{~d} * \mathrm{c}) /(\alpha * 1 \mathrm{~h})) *\left(\mathrm{Tair}(0)+\mathrm{I}_{\text {solar }} / \alpha+\mathrm{T}(-1)\right.\right. \\
& *((\rho * \mathrm{~d} * \mathrm{c}) /(\alpha * 1 \mathrm{~h})-1 / 2)))+(1 /(1 / 2+(\rho * \mathrm{~d} * \mathrm{c}) /(\alpha * 1 \mathrm{~h})) \\
& *(((\rho * \mathrm{~d} * \mathrm{c}) /(\alpha * 1 \mathrm{~h})-1 / 2) *(\operatorname{Tair}(0)-\mathrm{T}(-1))) \quad\left[{ }^{\circ} \mathrm{C}\right]
\end{aligned}
$$




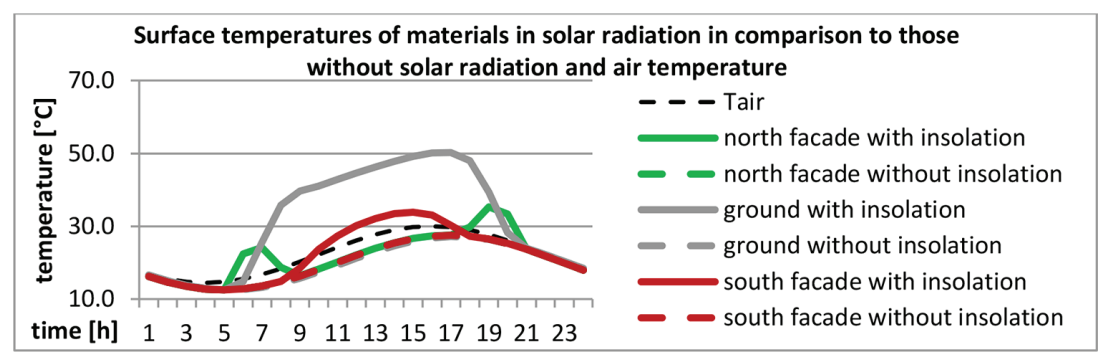

Figure 5: Surface temperatures in a street canyon with north and south facing brick facades (south façade in sun 9 am to $5 \mathrm{pm}$, north façade in early morning and late evening) and ground with tarmac, calculated with analytical model eqn (10).

Figure 5 shows results of this model for different materials (tarmac for ground in sun, dark bricks on both north and south facade; north facade is in sun in early morning and late evening, south facade from about 9 am to $5 \mathrm{pm}$ ). For comparison temperatures of materials in Tair (see 4.2) as well as Tair are added. The results show a good accordance with measurements [3-5].

\section{RESULTS}

\subsection{Typical street canyon without measures}

For the investigations a typical street canyon of $18 \mathrm{~m}$ width and $18 \mathrm{~m}$ height (thus ratio $1: 1$ ) was chosen. This should be the most frequent type in most of the (European) cities and corresponds with 5-storey buildings and a two line street with parking lots and sidewalks. Figure 6 shows the typical situation with dark bricks on south and north façade and tarmac on ground, the different lines correspond to different positions of a person in the canyon, in the middle of the street (UTCI 1, pedestrian zone), near north facade (UTCI 2, sidewalk) and near south facade (UTCI 3, sidewalk).

It can be seen that the direct solar radiation strikes directly on the person increases UTCI by nearly $6 \mathrm{~K}$ leading to strong heat stress. The person on the sidewalk near the north facade receives sun only in the early morning and the late evening, the person near the south facade

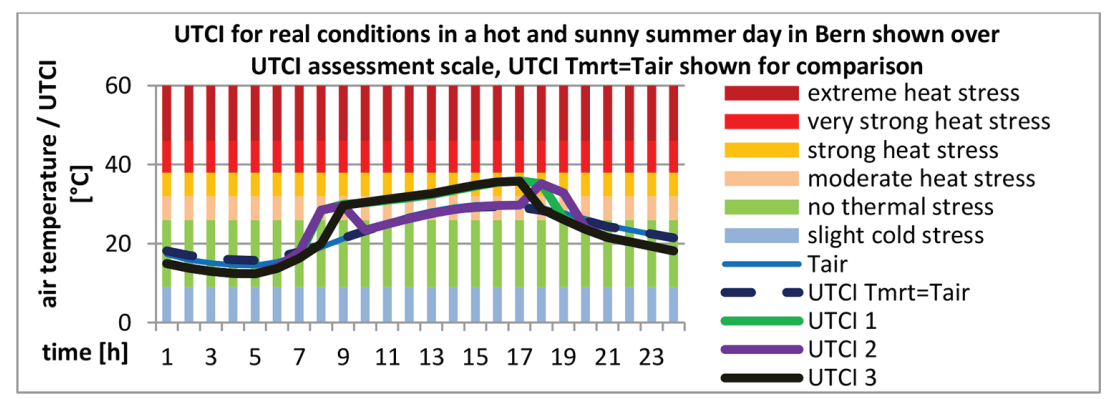

Figure 6: UTCI for a person in a canyon with brick facades, tarmac on ground with positions: UTCI 1 middle (pedestrian zone), 2 north façade (sidewalk) and 3 south façade (sidewalk). 
is in sun until $5 \mathrm{pm}$ while the person in the middle stays one hours longer in sun (sun is shining along the canyon).

\subsection{Impact of shading}

The impact of shading is shown in Fig. 7. UTCI 1 holds for a person on the sidewalk near the south facade under a sun umbrella (the street canyon remains in sun), the reduction in UTCI of $6 \mathrm{~K}$ nearly down to the line Tmrt = Tair is remarkable! If the whole street canyon is set into shadow (like it is done in some streets in southern countries with fabric or else) receiving only diffuse radiation (UTCI 2) UTCI is further reduced by more than $3 \mathrm{~K}$ !

\subsection{Impact of materials and colors}

In general it is assumed in the physical model that radiation from sun or sky striking on a material's surface is reflected (albedo) or absorbed (reflection + absorption=1). Low values in albedo lead to high absorption and high temperatures. Vice versa high values in albedo lead to low temperatures but to high reflection of solar radiation to the person.

\subsubsection{Ground}

The person is assumed as to be in the middle of the sunlit canyon. We change the materials of the ground according to UTCI $1=$ marble, UTCI $2=$ natural stone (pavement) and UTCI $3=$ tarmac. Figure 8 shows the result which seems to be a bit surprising: The bright marble

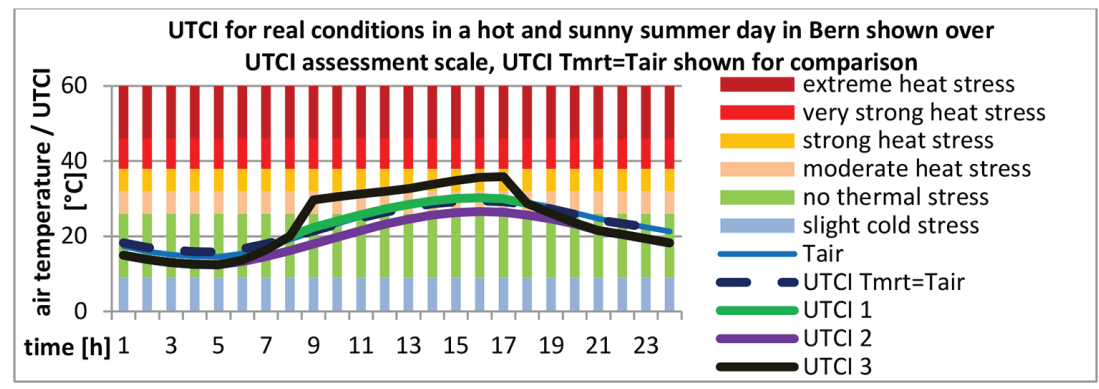

Figure 7: UTCI for a person near the south façade, brick facades and tarmac: UTCI 1 only person in shadow; 2 person, facades and ground in shadow and 3 all in sun.

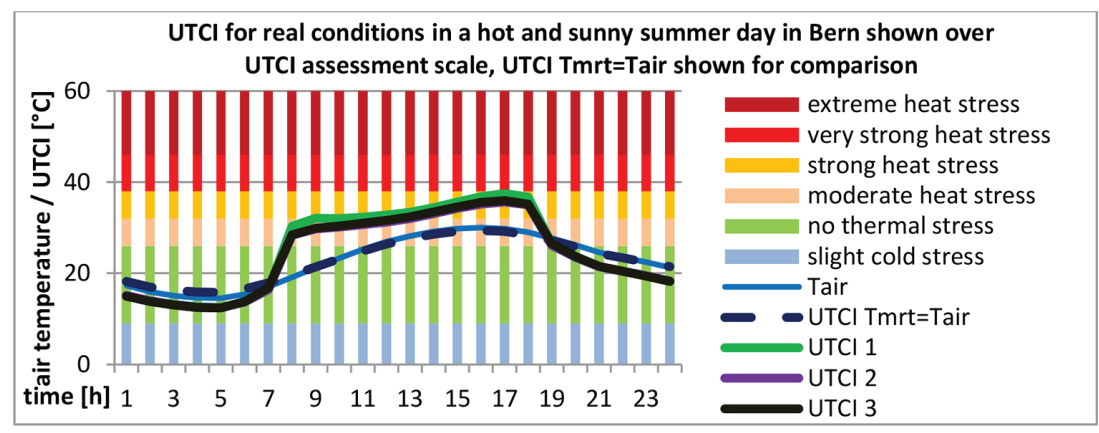

Figure 8: UTCI for a person in the middle of the canyon and in sun. Different ground materials show differences in UTCI: 1 - marble, 2 - pavement, 3 - tarmac. 
shows the highest UTCI during the day! The difference to the other two is about 1 to $1.5^{\circ}$. The best behaviour shows natural stone (pavement), grey concrete should have quite similar values (not shown here).

A more detailed investigation shows that the high reflecting marble (albedo 60\%) increases heat stress (UTCI $34.4^{\circ} \mathrm{C}$ ) because of its high reflection of solar radiation to the person. In spite of that marble remains the material with the lowest temperature $\left(23.0^{\circ} \mathrm{C}\right)$ because it absorbs less. Of course tarmac shows the highest temperature because of the high absorption $\left(37.9^{\circ} \mathrm{C}\right)$ but the resulting thermal (IR) radiation given back to the person is spread over a longer period therefore the resulting heat stress is lower.

Finally it can be recommended that for a lower heat stress during the day for the ground material a good compromise between reflection and absorption should be chosen (it may be that the best combination here depends on the location and its climate and should be optimized again!). For moderate / Mediterranean climate natural stone (pavement) or concrete show the best results. But the ground has also other purposes to fulfil than only to care for thermal comfort of a standing person (with shoes). The ground invites also to walk/stay bare foot, to sit or to lie. Then the direct contact with the surface determines comfort and a brighter material which stays cooler should be chosen.

\subsubsection{Facades}

First we assume natural stone as best material for the ground for the following investigations. The influence of facades in sun on thermal comfort is the highest for a person who is near to the sunlit south façade, we chose this position. We investigate the impact of heavy and light, dark and bright façade materials. The best behaviour is shown by dark bricks (UTCI $33.3^{\circ} \mathrm{C}$, temperature $30.3^{\circ} \mathrm{C}$ ). Again the effect of higher reflection of solar radiation dominates the one of higher temperature and IR radiation. The more inert bright concrete stays remarkably cooler $\left(24.3^{\circ} \mathrm{C}\right)$ than bricks but regarding UTCI $\left(34.2^{\circ} \mathrm{C}\right)$ this effect is less dominating than the high reflection of solar radiation. A comparison between light and heavy materials shows that the impact on of thermal mass (plaster/brick) is with some tenth of a degree nearly negligible while the impact of colours (bright/dark) on UTCI dominates with about $1^{\circ}$ (e.g. bright/dark plaster UTCI $34.6 / 33.4^{\circ} \mathrm{C}$ ).

\subsubsection{Special measures: Green facades and low IR emission (low- $\varepsilon$ ) paint}

According to [4] special low emissivity paints can reduce the emissivity from 0.9 down to 0.6. Such paint is assumed as bright. A green façade transfers about $50 \%$ of the received solar radiation into evaporation $[3,5]$ thus contributing neither to absorption nor to reflection. For the remaining $50 \%$ it is assumed that $15 \%$ are reflected and $35 \%$ absorbed.

The best behaviour is shown by green facades as well as by low IR emissivity paint. The improvement in UTCI is remarkable and in the range of $2^{\circ}$. But the low IR emissivity paint reduces IR radiation also during night (person is cooled by cold and clear sky but not heated by IR radiation from facades) leading to a reduction in UTCI of up to $4^{\circ}$ and slight cold stress - people will feel a bit cold, more than with non-coated facades. In moderate climates this may cause supplementary discomfort and cold stress in cold periods. The use low IR emissivity paint should be planned regarding all seasons of a year. Because of similar values for absorption of solar radiation the temperatures of all three facades are very similar. In spite of that and induced by the other quantities UTCI shows differences. 


\section{DISCUSSION}

For the detailed investigation of thermal comfort (assessed according to UTCI index) in street canyons with a simple but holistic model was developed. All investigations in this paper were done for a moderate to Mediterranean climate. For other climates the results and recommendations may be different and the investigations should be repeated!

Shading has the highest impact on UTCI. Bringing persons into shadow (with sun umbrellas, awnings etc.) reduces UTCI by about $6^{\circ}$, shading of the whole street canyon (fabric, trees) reduces UTCI by another $2^{\circ}$.

The material for the ground should be a good compromise between absorption and reflection. Dark (and massive) materials behave better than bright ones. Otherwise a dark surface becomes hot, but the ground should also invite persons to stay bare foot, to sit or lie on it. Then brighter and cooler materials should be chosen.

The special measures green facades and low IR emissivity paint have a remarkable impact on UTCI with up to $2^{\circ}$ reduction during the day. Low IR emissivity paints reduce UTCI also during night (remarkably, up to $4^{\circ}$ !) and can lead in summer to slight cold stress, more than the classical facades. It may be less comfortable for persons sitting on terraces in front of facades during night. The same effect will happen of course during cold periods increasing discomfort and cold stress. Low IR emissivity paint could be a good measure for locations where heat stress is the only problem, for locations with hot and cold periods one should reflect the impact on comfort in all the situations around the year before using it.

Green facades behave different, like an adaptive measure. The highest evaporation and cooling effect occurs if the sun is shining, during night time it behaves like a classical material. Here darker facade materials behave better than bright ones; the difference in UTCI is about $1^{\circ}$. The effect of reflection of solar radiation from sun and sky from facades and ground to the persons dominates the one of absorption and IR radiation from facades and ground to the person. The influence of thermal mass (brick, concrete versus plaster, cladding etc.) is very small, in UTCI only some tenth of a degree.

Literature reports often about temperature measurements of different façade materials. The results are in accordance with our findings but the assumption that a cooler façade leads necessarily to higher comfort is not correct. The effect of reflection of solar radiation to the persons is dominating and has to be included in the investigations simultaneously.

The conclusion that darker materials behave better than brighter ones seems to be in contradiction to the typical bright and white facades of many traditional buildings in Mediterranean climate. Here the central target was to reach a maximum of comfort indoor in the evening / night time to have a good sleep. White facades shall reflect as much as sunlight as possible to avoid absorption and transfer of heat into the interior if the building. Today in new buildings we have normally a layer of thermal insulation that breaks heat transfer completely - we can concentrate on outdoor comfort.

\section{REFERENCES}

[1] UTCI, available at: http://utci.org/, (Accessed 20 December 2016).

[2] Bludau, Chr., Zirkelbach, D. \& Künzel, H., Condensation Problems in Cool Roofs, presented at DBMC International Conference on Durability of Building Materials and Components ISTANBUL, Turkey 11-14 May 2008, 
[3] Susorova, I. Angulo, M. Bahrami, P. \& Stephens, B., A model of vegetated exterior facades for evaluation of wall thermal performance. Building and Environment, 67, pp. 1-13, 2013. https://doi.org/10.1016/j.buildenv.2013.04.027

[4] Zillig, W., Lenz, K., Sedlbauer, K. \& Krus, M., Condensation on façades - influence of construction type and orientation, available at: www.irbnet.de/daten/iconda/CIB2387. pdf. (Accessed 20 December 2016).

[5] Karunarathne A., Modelling of Thermal Effects due to Solar Radiation on Concrete Pavements , available at: iiirr.ucalgary.ca/files/iiirr/109.pdf. (Accessed 20 December 2016).

[6] Schmidt, M., Gebäudebegrünung und Verdunstung, TU Berlin, available at: http://www. helix-pflanzensysteme.de/de/content/articles/gebaeudekuehlung-durch-vegetation-56/. (Accessed 20 December 2016)

[7] Available at: http://www.helix-pflanzensysteme.de/de/content/articles/fassadenbegruenung-mit-hedera-helix-woerner-reduziert-die-erwaermung-des-stadtklimas-69/. (Accessed 20 December 2016).

[8] Zinzi, M. \& Agnoli, S., Cool and green roofs. An energy and comfort comparison between passive cooling and mitigation urban heat island techniques for residential buildings in the Mediterranean region. Energy and Buildings, 55, pp. 66-76, 2012. https://doi.org/10.1016/j.enbuild.2011.09.024

[9] Glossary of terms for thermal physiology. Journal of Thermal Biology, 28, pp. 75-106, 2003. https://doi.org/10.1016/s0306-4565(02)00055-4

[10] VDI 3787 part 2: Environmental meteorology methods for the human biometeorological evaluation of climate and air quality for urban and regional planning at regional level. Part I: Climate. VDI Verlag, November 2008.

[11] View factors, available at: http://www.thermalradiation.net/indexCat.html. (Accessed 20 December 2016)

[12] Meteonorm, available at: http://www.meteonorm.com/. (Accessed 20 December 2016) Heat transfer equation, available at: http://www.uni-magdeburg.de/isut/TV/Download/ Kapitel_7_Waerme-_und_Stoffuebertragung.pdf. (Accessed 20 December 2016). 